pupils and assistants, once they had accustomed themselves to his austere manner and to his exacting and critical methods. Elected a foreign member of the Royal Society in 1899 (he had been awarded the Davy Medal in 1890) and recipient of the Nobel Prize for Chemistry in 1902, he died during the night of July 14, 1919.

\section{An Elizabethan Lodestone}

The National Maritime Museum, Greenwich, has recently been lent a lodestone reputed to have belonged to Sir Francis Drake and to have been given by him to Lawrence Kemeys. The lodestone is mentioned in an inventory of the possessions of the Kemeys family so far back as 1630, and has been handed down in the family to Lord Wharton, its present representative, by whose permission it is being exhibited in the Museum. It is approximately 1 in. by 1 in. by $\frac{5}{8} \mathrm{in}$. and is believed to have been reset in silver about 1700 . The lodestone is of the type formerly carried by sea-captains when on long voyages in order to 'retouch' the compass needles when they became demagnetized. 'I'his one is extremely strong, having a magnetic moment of 1,900 c.g.s. units. Lawrence Kemeys came of the Kemeys, or Kemmeys, family of Cefn Mably House, Michaelstone, near Cardiff, and the earliest record usually quoted of him is his command of the Gallego under Sir Walter Raleigh during his voyage to Trinidad and up the Orinoco in 1595. He seems to have shared for a time Raleigh's imprisonment in the Tower of London in 1603, and was foremost in urging the undertaking of the latter's ill-fated expedition to the Orinoco of 1617.

\section{Ramsay Centenary Exhibition}

As exhibition at the Science Museum, organized in collaboration with University College, London, marks the centenary of the birth of Sir William Ramsay (see p. 554); it will be open for three months. The Exhibition is divided into three main sections: the first will include books, documents, portraits and general biographical material. A large oil painting of Ramsay, made by Mark Milbanke in 1913, will form a fitting centre-piece. In the second group will be seen some of the original apparatus used by Ramsay and his collaborators. One of the earliest machines for obtaining liquid air, which was installed for Ramsay in 1898, has been re-erected for the exhibition. The third group illustrates the way in which the inert gases now serve our needs.

\section{Incubation and Hatchery Practice}

Every year in England and Wales about 100,000,000 poultry eggs are used for hatching purposes ; of these, about 30 per cent fail to hatch. Failure to hatch may be due to unsatisfactory nutrition of the breeding flock or it may be due to some fault of the hatchery incubating the eggs. Whatever the cause, a 30 per cent loss represents a heavy charge on the poultry industry of Britain. Of equal or greater importance may be the effect of unsatisfactory hatching conditions on chicks which do survive any mismanagement at the hatchery. They may be affected to a degree which may adversely influence their ability as egg producers, and these poor-quality birds will remain an additional handicap on the poultry industry. To help poultry farmers the Ministry of Agriculture and Fisheries has produced a booklet which deals with the hatchery industry in considerable detail. The opening section describes the structure of the egg and the development of the embryo chick. Natural hatching and artificial incubation are then dealt with, and hatchery design, construction, hygiene and management are also described. A chart summarizes all the possible causes of hatching failure and how to avoid them, while the special requirements of turkey, duck and goose eggs are listed in an appendix. Copies of the bulletin may be obtained from H.M.S.O., price $1 s .10 \frac{1}{2} d$.

\section{Detection of Insects in Grain}

To reveal the extent to which a sample of grain is infested by insects and the nature of the insects concerned, a prolonged investigation in the laboratory which may take several weeks is required. But there is frequent need for some rapid method by which the presence or absence of living insects can be recognized, so that an immediate decision may be reached as to whether the grain in question is suitable for prolonged storage. Similarly, in stores receiving supplies from various sources, testing of incoming batches will prevent the addition of infested samples to the main stocks. 'The 'heating' of stored grain is a well-known sign of infestation, but a much more sensitive method for the detection of insects in grain is their production of carbon dioxide. At or below 15 per cent water content, the metabolism of the grain itself or of any micro-organisms it may contain is negligible in comparison with that found even with a minimal amount of insect infestation. R. W. Howe and 'T. A. Oxley, of the Pest Infestation Research Laboratory, Department of Scientific and Industrial Research, have written a concise statement of the principles and applications of the carbon dioxide method in a pamphlet entitled "Detection of Insects by their Carbon Dioxide Production" (pp. 20; London: H.M.S.O., 1952 ; $1 s$. net). This describes the apparatus required, the test procedure and the interpretation of results, and includes all the tables needed for the analysis.

\section{Agriculture and Forestry}

A STUDY of alluvial soils in north-west Germany from the point of view of combining alternate forestry and agriculture in a periodic or temporary agricultural use of forest land has been made by W. Wittich, and his conclusions have now been published in a brochure entitled "Landwirtschaftliche Zwischennutzung im Walde als Meliorationsmittel und Hilfe für die Ernährung" (temporary agricultural cropping on forest land as a means of soil improvement and as a supplementary source of foodstuffs) (Hannover: M. and H. Schaper, 1948) (see Forestry Abstracts, 13, No. $3 ; 1952$. From the Commonwealth Forestry Bureau, Oxford). He reviews German, Austrian and Swiss literature on the subject, considering the varying characteristics of forest soils, the types of soil suitable for this purpose, the requirements of the agricultural crop plants that could be used, the practical management of such crops and the prospects for agricultural cropping on individual soil types, with main reference to the diluvial and alluvial soils of north-west Germany. He concludes that the widespread prejudice against this practice, one of the earliest practised by man, in part at least, is untenable; and he maintains that there are few soils on which agricultural use need be detrimental and many in which definite improvements could be achieved under proper treatment-for example, by the more intensive cultivation and fertilizing made economically possible by agricultural crops. This investigation, 